\title{
The Effect of Metoclopramide Administration on Electrolyte Status and Activity of Renin- Angiotensin-Aldosterone System in Premature Infants
}

\author{
E. SULYOK, T. ERTL, L. VARGA, J. BÓDIS, AND I. F. CSABA \\ Department of Obstetrics and Gynecology, University Medical School, Pécs, Hungary
}

\begin{abstract}
The present study has been carried out to define whether endogenous dopamine contributes to the regulation of renal sodium handling and the function of the renin-angiotensin-aldosterone system in low birth weight premature infants. Twelve premature infants with mean birth weight of $1420 \mathrm{~g}$ and mean gestational age of 29.2 wk were given metoclopramide (MTC) in a dose of $0.1 \mathrm{mg} /$ $\mathrm{kg} /$ day to treat delayed gastric emptying, regurgitation, and abdominal distension at the age of 17-23 days. Infants were kept on either a low (2-3 mEq/ $\mathrm{kg} / \mathrm{day})$ or high (4-7 $\mathrm{mEq} / \mathrm{kg} /$ day) sodium diet to modulate activity of RAAS. Prior to and after a 3-day period of MTC administration, blood samples were taken, and in six male infants 24-h urine collections were made to determine plasma and urine electrolytes, plasma renin activity, plasma aldosterone concentration, and urinary aldosterone excretion. We demonstrated that plasma sodium and potassium concentrations and plasma renin activity were not altered by MTC. On the other hand, in response to MTC, there was a significant increase in urinary sodium excretion $(1.8 \pm 0.3$ versus 2.3 $\pm 0.3 \mathrm{mEq} / \mathrm{kg} / \mathrm{day}$ ) and a decrease in potassium excretion $(1.2 \pm 0.2$ versus $0.8 \pm 0.1 \mathrm{mEq} / \mathrm{kg} / \mathrm{day}) ;$ plasma aldosterone concentration and urinary aldosterone excretion decreased significantly from initial values of $2101 \pm 274 \mathrm{pg} /$ $\mathrm{ml}$ and $2.91 \pm 0.52 \mu \mathrm{g} / \mathrm{day}$ to $1500 \pm 207 \mathrm{pg} / \mathrm{ml}(p<0.01)$ and $2.21 \pm 0.43 \mu \mathrm{g} /$ day $(p<0.01)$, respectively, after MTC. These alterations were independent of the pretreatment hormone levels. We conclude that in low birth weight premature infants endogenous dopamine has no influence on plasma renin activity and enhances rather than inhibits aldosterone production and renal tubular sodium reabsorption. (Pediatr Res 19: 912-915, 1985)
\end{abstract}

\section{Abbreviations}

DA, dopamine

RAAS, renin-angiotensin-aldosterone system

PRA, plasma renin activity

pAldo, plasma aldosterone concentration

UAE, urinary aldosterone excretion

MTC, metoclopramide

In recent years several lines of evidence have suggested a role of DA in the regulation of renal sodium excretion and the involvement of dopaminergic mechanisms in the control of the

Received November 8, 1984: accepted April 17. 1985

Reprint address E. Sulyok. Department of Obstetries and Gynecology, University Medical School. H-7624 Pécs. Hungary.
RAAS system. Urinary DA excretion has been demonstrated to correlate positively with sodium intake and urinary sodium excretion (1-4), and a dose-dependent increase in urinary sodium excretion has been reported after DA administration (5-7) suggesting a natriuretic role for DA. Moreover, DA has been shown to increase renin release $(8-10)$, to inhibit angiotensin-induced aldosterone production (11-13), and to enhance the renal response to aldosterone (14).

Very few data are available on the interactions among dopaminergic mechanisms, sodium homeostasis, and the RAAS during the neonatal period. It has been observed, however, that DA given to sick premature infants in a dose of $0.5-4.0 \mu \mathrm{g} / \mathrm{min} / \mathrm{kg}$ increased sodium and water diuresis (15) and enhanced PRA, but did not cause significant alteration in pAldo (16). In an attempt to define the relationship between endogenous DA, renal sodium excretion, and the function of RAAS, the present study was designed to assess alterations in electrolyte status, PRA, pAldo, and UAE in premature infants who were given MTC, a specific DA antagonist.

\section{MATERIALS AND METHODS}

Twelve premature infants with a mean birth weight of $1420 \mathrm{~g}$ (range 990-1700 g) and mean gestational age of $29.2 \mathrm{wk}$ (range 28-31 wk) were selected for the study. They were given MTC in a dose of $0.1 \mathrm{mg} / \mathrm{kg} /$ day to treat delayed gastric emptying, regurgitation, and abdominal distension at a mean postnatal age of 20.5 days (range 17-23 days), as suggested by Sankaran et al. (17). Eight of the 12 infants were kept on high sodium (4-7 $\mathrm{mEq} / \mathrm{kg} /$ day); four infants were on a low $(2-3 \mathrm{mEq} / \mathrm{kg} /$ day $)$ sodium diet to modulate activity of the RAAS. During the course of the study four infants on high sodium were given Penicillin $G$ and Kanamycin in a dose of $100,000 \mathrm{U} / \mathrm{kg} /$ day and $10 \mathrm{mg} / \mathrm{kg} /$ day, respectively, for a period of 6 days.

Before and after a 3-day period of MTC administration, blood samples were taken, and in the six male infants 24-h urine collections were made to determine plasma electrolyte concentration, PRA, pAldo and urinary electrolyte excretion, and UAE.

Blood samples were immediately placed in tubes in ice water containing EDTA (for PRA) or heparin (for pAldo). Plasma was separated in a refrigerated centrifuge and stored at $-20^{\circ} \mathrm{C}$ until assayed. Urine specimens were pooled and stored at $-20^{\circ} \mathrm{C}$ until analysis.

PRA, pAldo, and UAE was determined by radioimmunoassay according to the methods of Haber et al. (18) and Vetter et al. (19) using SORIN-CEA-IRE RIA kits. Sodium and potassium concentrations in plasma and urine were measured by flame photometry.

Statistical analyses were performed by calculating the coefficient of correlation regression equations and Student's paired $t$ 
test. Approval of the local ethical committee and informed parental consent were obtained for all studies.

\section{RESULTS}

As shown in Table 1 no significant change was observed in plasma sodium or potassium concentrations after MTC administration, although tendencies for a fall in plasma sodium and to rise in plasma potassium were seen.

Urinary sodium excretion increased significantly from the pretreatment level of $1.8 \pm 0.3$ to $2.3 \pm 0.3 \mathrm{mEq} / \mathrm{kg} /$ day $(p<$ 0.05 ) after MTC, and there was a moderate, but significant, reduction in urinary potassium excretion from $1.2 \pm 0.2$ to 0.8 $\pm 0.1 \mathrm{mEq} / \mathrm{kg} /$ day $(p<0.05)$.

When plasma and urinary electrolyte values of infants on high and low sodium intakes were studied separately, it was observed that infants on low sodium were hyponatremic and tended to increase their sodium excretion more in response to MTC than those on the high sodium intake. Due to the small numbers of cases, however, statistical significance was not reached for this observation.

Figure 1 demonstrates that PRA remained unaltered by MTC $(39.4 \pm 5.9$ versus $42.0 \pm 11 \mathrm{ng} / \mathrm{ml} / \mathrm{h})$, whereas in response to MTC treatment, there was a significant decrease in pAldo with mean levels falling from $2101 \pm 274$ to $1500 \pm 207 \mathrm{pg} / \mathrm{ml}(p<$ 0.01 ). Similarly, the UAE responded to MTC with a significant fall from $2.91 \pm 0.52$ to $2.21 \pm 0.43 \mu \mathrm{g} /$ day $(p<0.01)$. It is also evident in Figure 1 that PRA, pAldo, and UAE tended to be higher in infants on low sodium than in those on high sodium intake. Basal hormone levels, however, had no apparent influence on the response pattern induced by MTC.

Figure 2 shows a significant positive correlation between UAE and urinary $\mathrm{K} / \mathrm{Na}$ ratio suggesting that the high rate of sodium excretion is mainly due to suppressed aldosterone production.

\section{DISCUSSION}

Contrary to the general view, the results of the present study show that the administration of MTC, a specific DA antagonist, to premature infants results in an increase of urinary sodium excretion suggesting that endogenous DA may enhance renal tubular sodium reabsorption in this early period of life. The MTC-induced natriuresis was associated with a significant fall of pAldo and UAE and there was a significant positive correlation between UAE and urinary $\mathrm{K} / \mathrm{Na}$ ratio. It is likely, therefore, that the higher rate of urinary sodium excretion results from the decreased aldosterone production. Additionally, inhibiting a di- rect action of DA on renal tubular sodium reabsorption may be a complementary factor (20).

The involvement of DA in the control of renal sodium handling is far from clear. On the basis of the apparent parallelism between urinary sodium and DA excretion, a natriuretic effect

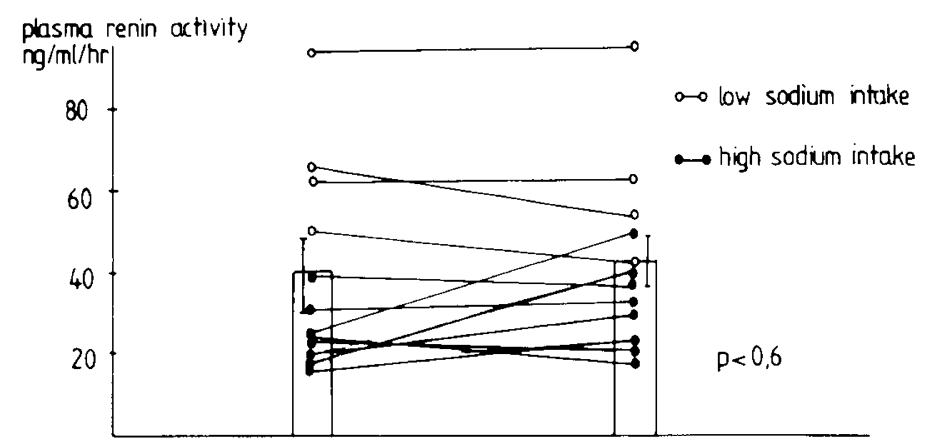

\section{plasma didosterone}

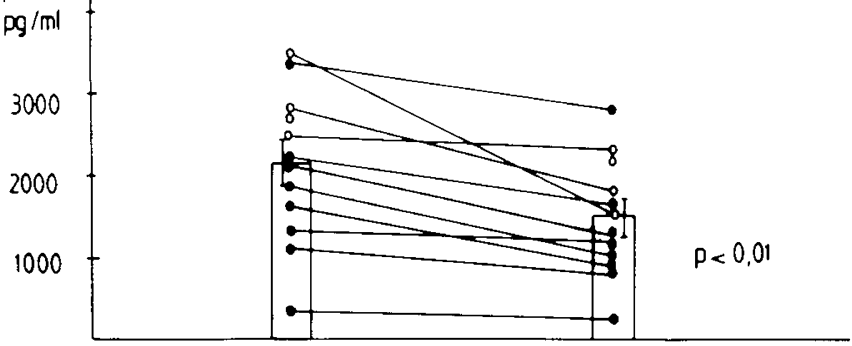

urinary abdosterone

excretion tug/day
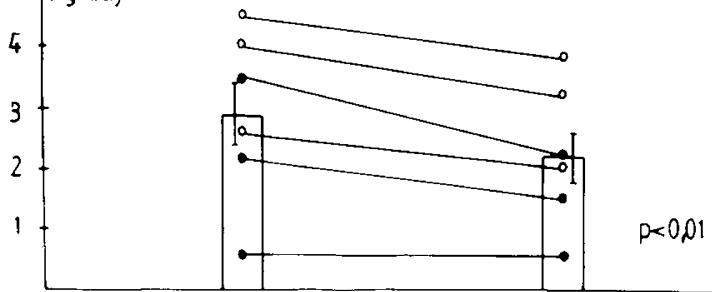

Fig. 1. Effect of metoclopramide treatment on plasma renin activity. plasma aldosterone concentration, and urinary aldosterone excretion in premature infants. The symbols represent values obtained before and after metoclopramide administration, respectively.

Table 1. Effect of metoclopramide treatment on plasma level and urinary excretion of sodium and potassium in premature infants on high and low sodium diet (mean $\pm S E$ )

\begin{tabular}{|c|c|c|c|c|}
\hline & \multicolumn{2}{|c|}{ Plasma concentration (mEq/liter) } & \multicolumn{2}{|c|}{$\begin{array}{l}\text { Urinary excretion }(\mathrm{mEq} / \mathrm{kg} / \\
\text { day) }\end{array}$} \\
\hline & Sodium & Potassium & Sodium & Potassium \\
\hline \multicolumn{5}{|c|}{ Before metoclopramide } \\
\hline High sodium & $\begin{array}{c}139.0 \pm 2.9 \\
n=8\end{array}$ & $\begin{array}{c}5.0 \pm 0.30 \\
n=8\end{array}$ & $\begin{array}{c}2.6 \pm 0.5 \\
n=3\end{array}$ & $\begin{array}{c}1.4 \pm 0.3 \\
n=3\end{array}$ \\
\hline Low sodium & $\begin{array}{c}130.7 \pm 1.3 \\
n=4\end{array}$ & $\begin{array}{l}5.6 \pm 0.2 \\
n=4\end{array}$ & $\begin{array}{c}0.9 \pm 0.1 \\
n=3\end{array}$ & $\begin{array}{c}1.0 \pm 0.2 \\
n=3\end{array}$ \\
\hline Total & $\begin{array}{c}136.0 \pm 2.5 \\
n=12\end{array}$ & $\begin{aligned} 5.1 & \pm 0.2 \\
n & =12\end{aligned}$ & $\begin{array}{c}1.8 \pm 0.3 \\
n=6\end{array}$ & $\begin{array}{c}1.2 \pm 0.2 \\
n=6\end{array}$ \\
\hline \multicolumn{5}{|c|}{ After metoclopramide } \\
\hline High sodium & $\begin{array}{l}136.9 \pm 2.7 \\
n=8\end{array}$ & $\begin{array}{c}5.2 \pm 0.3 \\
n=8\end{array}$ & $\begin{array}{l}2.8 \pm 0.4^{*} \\
\quad n=3\end{array}$ & $\begin{array}{c}1.0 \pm 0.3 \\
n=3\end{array}$ \\
\hline Low sodium & $\begin{array}{c}128.8 \pm 2.4 \\
n=4\end{array}$ & $\begin{array}{c}5.5 \pm 0.2 \\
n=4\end{array}$ & $\begin{array}{c}1.8 \pm 0.1 \\
n=3\end{array}$ & $\begin{array}{c}0.7 \pm 0.1^{*} \\
n=3\end{array}$ \\
\hline Total & $\begin{array}{c}134.1 \pm 2.2 \\
n=12\end{array}$ & $\begin{array}{c}5.3 \pm 0.2 \\
n=12 \\
\end{array}$ & $\begin{array}{c}2.3 \pm 0.3 \\
n=6\end{array}$ & $\begin{array}{c}0.8 \pm 0.1 \\
n=6\end{array}$ \\
\hline
\end{tabular}

$*_{p}<0.05$ 


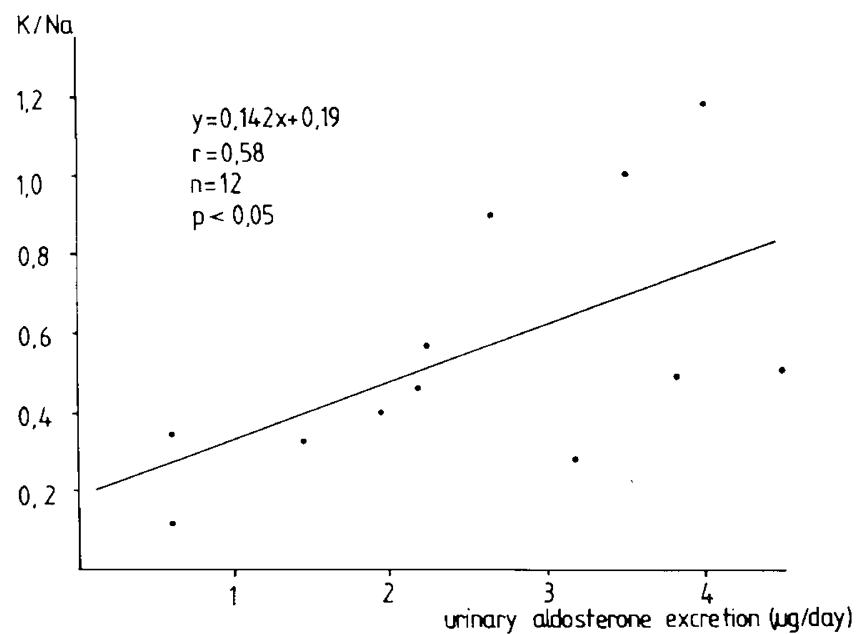

Fig. 2. The relationship of UAE to urinary $\mathrm{K} / \mathrm{Na}$ ratio in premature infants treated with metoclopramide.

of DA seemed likely (1-4). Several studies, however, questioned a role for DA as a physiological natriuretic hormone, since changes in urinary sodium and DA excretion could be dissociated $(3,21,22)$.

Further, the renal response to DA appears to be influenced by age. Pelayo and Jose (23) reported an age-dependent increase in DA-induced natriuresis in puppies. On the other hand Tulassay ct al. (15) demonstrated that therapeutic DA administration to sick premature infants produced a significant increase of sodium and water diuresis. No differences were noted, however, in the natriuretic response to DA in infants of various gestational and postnatal ages (15).

There is considerable evidence of an interrelationship between DA and the function of RAAS. It has been reported that DA given at a low rate has no apparent influence of PRA $(24,25)$, whereas DA infused at higher rates stimulated renin release $(8$, $10,24)$. The mechanism(s) by which DA increases renin release is uncertain. It may act either directly through dopaminergic and $\beta$-adrenergic stimulation or indirectly, as a result of a direct DAinduced natriuresis $(8,10)$.

In this regard DA administration to sick preterm neonates was found to be associated with a significant elevation of PRA (16). However, studies of DA blockade with MTC demonstrated variable effects on PRA: in response to MTC, PRA has been reported to remain unchanged $(6,12)$ to decrease $(27)$ or to increase $(28)$. When a rise occurred in PRA after MTC, the response was delayed and strongly influenced by the pretreatment PRA level. The greater PRA increment was seen in subjects on a low sodium diet with high prevailing PRA levels (28). In the present study MTC treatment of premature infants, either on a low or high sodium intake, failed to induce significant alterations in PRA, suggesting that endogenous DA is not involved directly in the control of renin release at any level of RAAS activity.

Concerning the role of DA in the regulation of aldosterone secretion, it has been suggested that DA might have a tonic inhibitory effect on angiotensin II-induced aldosterone production (12). In support of this notion it has been demonstrated that administration of DA or the DA agonist bromocriptine produced a significant suppression of the aldosterone response to angiotensin II, diuretics, and posture $(13,29-31)$. Moreover, MTC has been found to cause a rise in aldosterone secretion without changes in the known regulators of aldosterone production such as PRA, ACTH, electrolytes, and blood pressure $(12,32-34)$. Furthermore, the MTC-induced increment in plasma aldosterone concentration could be attenuated by simultaneous administration of DA $(26,33)$.

The general concept of dopaminergic inhibition of aldosterone secretion has been questioned (35) because of recent studies in rats, rabbits, and dogs which failed to demonstrate an increased aldosterone secretion after MTC $(36,37)$. These observations lend support to the view that the inhibitory effect of DA on aldosterone production is species specific. Nevertheless its consistency in humans and nonhuman primates has been adequately substantiated. However, there is evidence that MTC produces its effect on aldosterone production by nondopaminergic mechanisms as well (35).

During the neonatal period there are limited data on the dopaminergic control of aldosterone secretion. In a previous study we observed unaltered plasma aldosterone levels in DAtreated premature infants despite significant increases of PRA. The finding has been interpreted to indicate either that the angiotensin II-induced aldosterone production is overridden by the inhibitory effect of DA, or that, in the absence of DA inhibition, the immature adrenals are unresponsive to further stimulation by the renin-angiotensin system (16). The present results suggest that in low birth weight premature infants endogenous DA is enhancing rather than inhibiting aldosterone production. This assumption is consistent with several recent studies in various animal species in which an effect of MTC on aldosterone could not be demonstrated $(36,37)$.

In conclusion, the present study on MTC-treated premature infants suggests that, in this early period of life, endogenous DA has no apparent influence on PRA but, enhances aldosterone secretion by the immature adrenals. The MTC-induced fall in pAldo and UAE seems to be independent of the pretreatment hormone levels and may contribute to the increased urinary sodium excretion seen in premature infants treated with this drug.

\section{REFERENCES}

1. Alexander RW, Gill JR, Yamabe H, Lovenberg W, Kaiscr HR 1974 Effects of dietary sodium and acute saline infusion on the interrelationship between dopamine excretion and adrenergic activity in man. J Clin Invest 54:194200

2. Ball SG, Lee MR 1977 The effect of carbiodopa administered on urinary sodium excretion in man: Is dopamine an intrarenal natriuretic hormone? Br J Clin Pharmacol 4:115-119

3. Ball SG, Oates NS. Lee MR 1978 Urinary dopamine in man and rat: Effect of inorganic salts on dopamine excretion. Clin Sci Mol Med 55:167-173

4. Carey RM, Van Loon GR, Baines AD, Ortt EM 1981 Decreased plasma and urinary dopamine during dietary sodium depletion in man. J Clin Endocrinol Metab 52:903-909

5. Davis BB, Walter MJ, Murdaugh HV 1968 The mechanisms of the increase in sodium excretion following dopamine infusion. Proc Soc Exp Biol NY 129:210-213

6. Goldberg LI 1977 The pharmacologic basis of the clinical use of dopamine. Proc Roy Soc Med 70(suppl 2):7-13

7. McDonald RH Jr. Goldberg Ll, McNay JL, Tuttle EP Jr 1964 Effects of dopamine in man. Augmentation of sodium excretion, glomerular filtration rate and renal plasma flow. J Clin Invest 43:1116-1124

8. Imbs J, Schmidt M, Schwartz J 1975 Effect of dopamine on renin secretion in the anaesthetized dog. Eur J Pharmacol 33:151-157

9. Qucsada T, Garcia-Torres L, Alba F, Garcia Del Rio C 1979 The effects of dopamine on renin release in the isolated perfused rat kidney. Experientia 35:1205

10. Wilcox CS, Aminoff MJ, Kurtz AB, Slater JD 1974 Comparison of the renin response to dopamine and noradrenaline in normal subjects and patients with autonomic insufficiency. Clin Sci Mol Med 46:481-488

11. Brown RD, Billman GE, Kem DC, Stone HL, Jiang N-S, Kao P, Hogstad RI 1982 The effect of metoclopramide and dopamine on plasma aldosterone concentration in normal man and Rhesus monkeys, Macaca mulatta: a new model to study dopamine control of aldosterone secretion. J Clin Endocrinol Metab 55:828-832

12. Carey RM. Thorner MO, Ortt BM 1979 Effects of metoclopramide and bromocriptine on the renin-angiotensin-aldosterone system in man. Dopaminergic control of aldosterone. J Clin Invest 63:727-735

13. McKenna TJ. Island DP. Nicholson WE. Liddle GW 1979 Dopamine inhibits angiotensin stimulated aldosterone biosynthesis in bovine adrenal cells. J Clin Invest 64:287-291

14. Adam WR 1979 Enhancement by L-dopa of the renal excretion of aldosterone in the rat. Clin Exp Pharmacol Physiol 6:87-96

15. Tulassay T, Seri I. Machay T. Kiszel J, Varga J, Csömör S 1983 Effects of dopamine on renal functions in premature neonates with respiratory distress syndrome. Int J Pediatr Nephrol 4:19-23

16. Sulyok E, Seri I. Tulassay T, Kiszel J, Ertl T 1985 The effect of dopamine administration on the activity of renin-angiotensin-aldosterone system in sick preterm infants. Eur J Pediatr 143:191-193 
17. Sankaran K, Yeboah E. Bingham WT, Ninan A 1982 Use of metoclopramide in preterm infants. Dev Pharmacol Ther 5:114-119

18. Haber E. Korner T. Page LB. Kliman B. Purnode A 1969 Application of radioimmunoassay for angiotensin $I$ to the physiologic measurement of plasma renin activity in normal human subjects. $\mathbf{J}$ Clin Endocrinol Metab 29:1349-1355

19. Vetter W, Vetter H. Siegenthaler W 1973 Radioimmunoassay for aldosterone without chromatography. 2. Determination of plasma aldosterone. Acta Endocrinol 74:558-567

20. Sulyok E, Gyódi Gy, Erthl T. Bódis J. Hartmann G 1985 The influence of $\mathrm{Na}$ Cl supplementation on the postnatal development of urinary excretion of noradrenaline, dopamine and serotonin in premature infants. Pediatr Res $19: 5-8$

21. Cuche JL. Selz F. Ruget G. Jondeau G, Guedon J 1983 Is dopamine a physiological natriuretic hormone in the dog? Clin Sci 65:479-486

22. Lee MR 1982 Dopamine and the kidney. Clin Sci $62: 439-448$

23. Pelayo JC, Jose PA 1982 The influence of age on the renal effects of dopamine/ Abstract/Pediatr Res 16:129A

24. Ball SG. Tree M. Morton JJ. Inglis GC, Fraser R 1978 Circulating dopamine: its effect on the plasma concentrations of catecholamines, renin, angiotensin. aldosterone and vasopressin in the conscious dog. Clin Sci 61:417-422

25. Cholshi DS, Yeh BK. Samet P 1972 Effects of dopamine and isoproterenol on renin secretion in the dog. Proc Soc Exp Biol Med 140:54-57

26. Carey RM. Thorner MO. Ortt EM 1980 Dopaminergic inhibition of metoclopramide-induced aldosterone secretion in man. J Clin Invest 66:10-18

27. Sowers JR. Tuck ML. Golub MS. Sollars EG 1980 Dopaminergic modulation of aldosterone secretion is independent of alterations in renin secretion. Endocrinology 107:937-941
28. Sowers JR, Golub MS, Eggena PH. Catania RA 1982 Influence of sodium homeostasis on dopaminergic modulation of aldosterone, renin, and prolactin secretion in man. J Clin Endocrinol Metab 54:121-126

29. Birkhauser M, Biondel A, Vallotton MB 1979 Bromocriptine induced modulation of plasma aldosterone response to acute stimulations. Acta Endocrinol 91:294-302

30. Edwards CRW Miall PA, Hanker JP. Thorner MO, Al-Dujaili EA, Besser GM 1975 Inhibition of the plasma aldosterone response to furosemide by bromocriptine. Lancet 2:903-904

31. Whitfield L, Sowers JR. Tuck ML, Golub MS 1980 Dopaminergic control of plasma catecholamine and aldosterone responses to acute stimuli in normal man. J Clin Endocrinol Metab 51:724-729

32. Norbiato G, Bevilacqua M, Raggi U. Micossi P, Morani C 1977 Metoclopramide increases plasma aldosterone concentration in man. $\mathrm{J}$ Clin Endocrinol Metab 45:1313-1316

33. Noth RH, McCallum RW, Contino C, Havelick J 1980 Tonic dopaminergic suppression of plasma aldosterone. J Clin Endocrinol Metab 51:64-69

34. Sowers JR, Brickman AS, Sowers DK. Berg G 1981 Dopaminergic modulation of aldosterone secretion in man is unaffected by gluccocorticoids and angiotensin blockade. J Clin Endocrinol Metab 52:1078-1084

35. Ganguly A 1984 Dopaminergic regulation of aldosterone secretion: how credible? Clin Sci 66:631-637

36. Sowers JR. Sharp B, Levin ER. Golub MS, Eggena P 1981 Metoclopramide, a dopamine antagonist stimulates aldosterone secretion in rhesus monkeys but not in dogs or rabbits. Life Sci 29:2171-2175

37. Campbell DJ, Mendelsohn FAO, Adam WR, Funder JW 1981 Mctoclopramide does not elevate aldosterone in the rat. Endocrinology 109:1484-1491 